\title{
Reliability in the whole life cycle of building systems
}

Article

Accepted Version

Wu, S., Clements-Croome, D. J., Fairey, V., Neale, K., Albany, B., Sidhu, J. and Desmond, D. (2006) Reliability in the whole life cycle of building systems. Engineering, Construction and Architectural Management, 13 (2). pp. 136-153. ISSN 09699988 doi: https://doi.org/10.1108/09699980610659607 Available at https://centaur.reading.ac.uk/12456/

It is advisable to refer to the publisher's version if you intend to cite from the work. See Guidance on citing.

To link to this article DOI: http://dx.doi.org/10.1108/09699980610659607

All outputs in CentAUR are protected by Intellectual Property Rights law, including copyright law. Copyright and IPR is retained by the creators or other copyright holders. Terms and conditions for use of this material are defined in the End User Agreement.

\section{www.reading.ac.uk/centaur}

\section{CentAUR}

Central Archive at the University of Reading 
Reading's research outputs online 


\title{
Reliability in the whole life cycle of building systems
}

\author{
Shaomin $\mathrm{Wu}^{\mathrm{a} 1}$, Derek Clements-Croome ${ }^{\mathrm{a}}$, Vic Fairey ${ }^{\mathrm{b}}$, Keith Neale ${ }^{\mathrm{b}}$ \\ ${ }^{\mathrm{a}}$ School of Construction Management and Engineering, The University of Reading, RG6 6AW, UK. \\ ${ }^{\mathrm{b}}$ Dytecna Ltd. 72 Barwell Business Park, Chessington, Surrey, KT9 2NZ, UK
}

\begin{abstract}
As the business environment becomes increasingly more competitive, it is essential that all available resources are used optimally and effectively. The need to place reliability at the forefront of design for building systems is becoming increasingly important, as operational failures, inadequate maintenance policies and logistic support issues, directly and/or indirectly, affect the through life performance and adversely affect business. Reliability analysis and its' implementation will lead to an improved whole life performance of the building systems. This paper analyses reliability impacts on the whole life cycle of building systems. It also reviews the up-to-date approaches adopted in UK construction, based on questionnaires designed to investigate the use of reliability within the industry. Suggestions on the use of reliability analysis in design are finally made in the paper.
\end{abstract}

Keywords: Reliability design, maintainability design, building systems, through life business model, maintenance policy

\section{Introduction}

Building systems encompass mechanical, electrical, security, safety, information and communication systems. The systems are installed to support the required business functions of the building, so it is essential that they can be carried out without interruption in meeting the users' needs, through reliability resulting in cost effectiveness throughout the whole life cycle. Since building systems are complex and encompass many different kinds of components, the ability of the systems to continually perform interactively is of vital importance.

Reliability defines the ability of a system or component to perform its required functions under stated conditions for a specified period of time (IEEE, 1990). Reliability is an essential factor used in assessing the performance of a building services system. Poor reliability directly or indirectly affects health, security and safety, as well as business continuity, and systems with high reliability may offer opportunities for less maintenance.

Evidence shows that the cost for the operation and maintenance of a building system is a significant element of its' life cycle cost (LCC). On the basis of research in office building services systems, Evans et al. (1998) have identified life cost ratio covering initial capital costs; maintenance and building operating costs; and business operating costs. They found that maintenance and operating

${ }^{1}$ Corresponding author: Dr. Shaomin Wu, e-mail: s.m.wu@kent.ac.uk

Suggested citation: $W u, S$. and Clements-Croome, D. and Fairey, V. et al. (2006) Reliability in the Whole Life Cycle of Building Systems. Engineering, Construction and Architectural Management, 13

(2). pp. 136-153. 
costs can be five times the capital costs; and the business operating costs can be two hundred times the capital costs over the life of the building. Therefore an improvement in designed reliability will reduce the LCC.

Reliability is associated with each stage of the whole life cycle of building systems. Prior research on reliability analysis for building systems has been directed mainly towards certain specific equipment. The whole life performance and LCC of building systems have also been researched (John et al., 2003, El-Haram et al., 2002). There is little research on investigating reliability impact at each stage of the whole life cycle of building systems.

The objective of this paper is to highlight the impact of reliability on each stage of the whole life cycle of building systems, to enable re-designed processes and methodologies to be developed to improve the whole life performance of the systems.

An in-depth understanding of the reliability of building systems needs to investigate all of reliabilityassociated aspects in the whole life of the systems. This paper reviews these aspects from top to bottom. The paper is structured as follows. Section 2 presents the possible failure patterns in building systems. In section 3, the main impacts of reliability are investigated for each stage of the whole life cycle of building systems. Section 4 analyses a questionnaire aimed at investigating the current status of the application of reliability analysis in construction in the UK. Finally, section 5 closes the paper with a discussion of the findings and some plans for future work.

\section{Failure patterns}

The typical graph of failure arisings against time is shown by the well-known, traditional "bathtub" curve at Figure 1. The curve is divided into three segments: an infant mortality period, usually marked by a rapidly decreasing failure rate; a random failure period, where the failure rate continues at a steady level; and a period of increasing failure rate representing the onset of product wear-out.

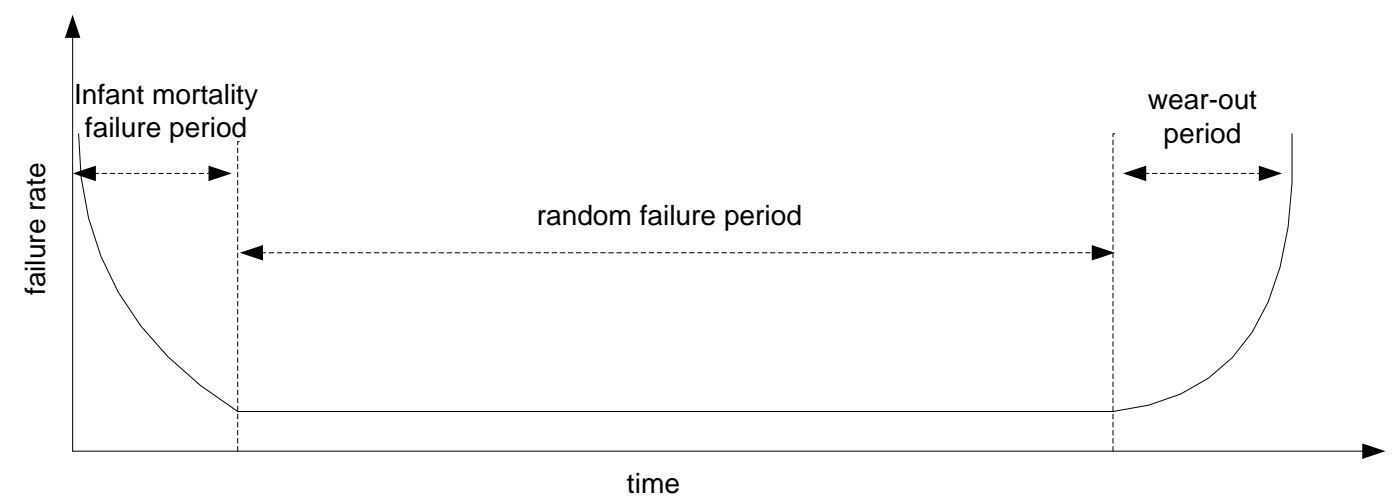

Figure 1: Bathtub curve

Different types of failures may occur within the three periods. From a client satisfaction perspective, infant mortalities are unacceptable. They are caused by design deficiencies of the product, poor quality control, process control or workmanship during manufacture or installation. In the central portion random failures are mainly caused by unpredictable occurrences, whilst predictable failures are overcome by scheduled maintenance. Within the wear-out period, failures become more prevalent due to the deterioration of the product, through use and/or "lifed" attributes 
Building systems show mainly six types of failure pattern. Figure 2 illustrates most of these failure distributions that may be found in a building and its' associated components (Bartlett and Simpson, 1998, Moubray, 1996):

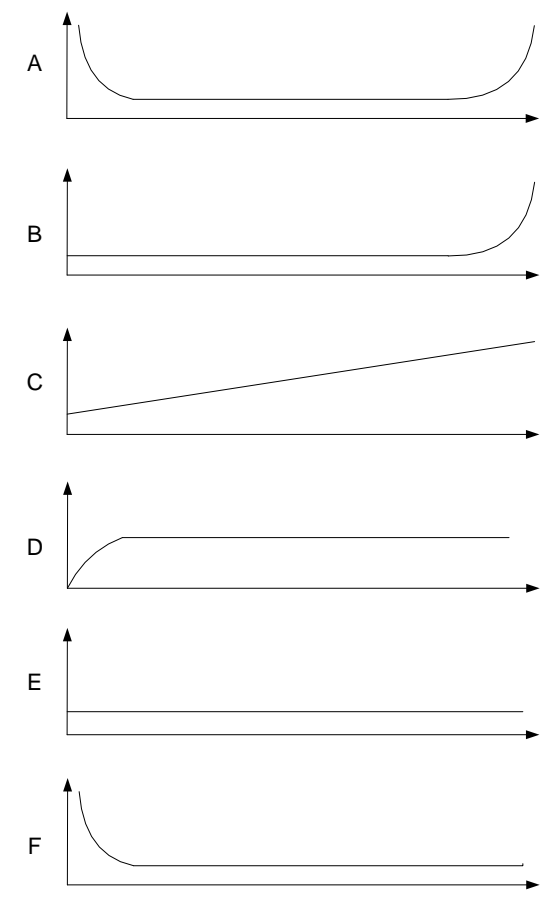

Figure 2 Failure patterns (Moubray, 1996)

A. "Bath-tub curve" with high incidence of failure (infant mortality) followed by random failure rate, then by a wear-out period;

B. Random or slowly increasing failure rate, ending in a wear-out period;

C. Slowly increasing rate, but there is no identifiable wear-out period;

D. Low failure rate when the item is new or just out of the shop, then a rapid increase to a constant level;

E. Random failure rate at the whole life;

F. High infant mortality, which drops eventually to a random or very lowly increasing failure probability

Moubray (1996) showed that in the Civil Aviation Industry, 4\% of items conform pattern A, 2\% to B, $5 \%$ to $\mathrm{C}, 7 \%$ to $\mathrm{D}, 14 \%$ to $\mathrm{E}$, and $68 \%$ to pattern $\mathrm{F}$.

Bartlett and Simpson (1998) states that patterns E and F are likely to become more common because mechanical and electrical building services components grow more complex.

As preventive maintenance is an option to apply when a failure rate is increasing, it is unnecessary to undertake any preventive maintenance on items with failure patterns D, E and F. We can therefore infer that most items in a building should not be suitable for preventive maintenance.

\section{Reliability in the whole life cycle of building systems}

There are several versions on the taxonomy of stages in the whole life of building systems. For example, John et al. (2003) suggest that there are five stages: typically these are client requirements and briefing, design, installation and commissioning, operations and maintenance, and 
disposal/reusing/recycling phases; Evans et al. (1998) divide the life cycle into three stages: design and construction, operational period, and demolition/recycling. As the taxonomical method from John et al is more detailed, we adopted this method in the paper. Reliability starts from the client requirements and briefing. The installation, operation and maintenance are important issues affecting reliability. If the equipment was designed with inherent poor reliability no matter how well it is installed, maintained and operated, it will remain unreliable until re-design action is carried out. Table 1 shows LCC elements that may be influenced by reliability.

\begin{tabular}{|l|l|}
\hline LCC category & LCC category cost element \\
\hline Client requirements \& Briefing & Requirement defining \\
& Requirement analysis \\
& Requirement translation \\
& Support Strategy \\
\hline Design & System integration \\
& Design trade-offs \\
& Materiel selection \\
& Quality control \\
& Configuration and change controls \\
& Repair policy \\
& Test strategies \\
& Repair/discard decisions \\
& Support solution analysis \\
& LCC analysis \\
\hline Construction, Installation $\&$ & Training \\
& Documentation \\
Commissioning & Packaging \& transportation \\
& Installation management \\
& Test \\
& Technical data \\
\hline Disposal/Reusing/Recycling & Effective maintenance \\
& Data collection \\
& Usage \\
& Training \\
\hline Operation \& Maintenance & Safety \\
& Replacement/renewal schemes \\
& Reusing/recycling \\
\hline
\end{tabular}

Table 1 LCC elements influenced by reliability

\subsection{Client Requirements \& Briefing}

Within the Support Strategy system reliability requirements and risk analysis should be introduced within the client's requirements and hence specified in the briefing. Typically, reliability requirements can be determined by considering the critical elements that are needed to meet the following conditions: business needs, cost drivers, needs of supply, statutory regulations, and robust management. Reliability requirements can be implemented by setting reliability allocations for elements, sub-systems and systems.

\subsection{Design}

System operational availability is a function of its reliability and maintainability (see Table 2). It is an important index that measures both reliability and maintainability. Maintainability is the degree with which a system can be maintained to optimise availability and minimise downtime. The reliability and 
maintainability of building systems should be fully understood by building designers, potential owners and building managers in order to design, install, operate and maintain them correctly and effectively. Appropriate design of reliability and maintainability can increase system's operational availability, ensure system performance and therefore increase business effectiveness.

\begin{tabular}{|l|l|l|}
\hline Reliability & Maintainability & Impact on Operational Availability \\
\hline No change & Increase & Increase \\
\hline No change & Decrease & Decrease \\
\hline Increase & No change & Increase \\
\hline Decrease & No change & Decrease \\
\hline
\end{tabular}

Table 2 Impact of reliability \& maintainability on operational availability

Reliability and maintainability attributes need to be incorporated as part of the design process and be formally addressed at design reviews. References on reliability and maintainability design can be found in military standards (MOD UK DEF STAN -00-41). However, there exists a difference between military needs and business needs. For example, systems may operate in extreme environments in the military domain, whereas building systems usually operate in less severe environments. The design for reliability and maintainability is the same but the impact of the environment may well create variations. In calculating the reliability of an item, the military influence the basic reliability (determined for ambient conditions) by factor increasing the predicted failure parts per million, in accordance with the specific environment in which it will be used. Therefore it is reasonable to assume that the same process may be used for the calculation of reliability in the construction domain. Many building services systems operate in extreme environments, therefore a similar factorisation system could be developed. Some organisations operate an empirical process for reliability factorisation. Typically in an airport the number of check-in counters may be increased to provide redundancy when failures occur. Alternatively the attainment at design of a check-in desk with improved reliability would provide a reduced capital cost (less check-in desks needed), improved availability leading to greater customer satisfaction and lower running cost due to reduced occurrence of failures.

Reliability and maintainability design for building systems can be undertaken from three levels: operating environment level, system structural level and component level. Figure 3 lists examples of considerations needed for reliability and maintainability design in the three levels.

Reliability design can be undertaken with the following three levels.

- Operating environment level. Since reliability of the system may be impacted by the environmental factors, stress-strength analysis; criticality may require the application of sensitivity analysis techniques. The major categories of stress are electrical, thermal, mechanical and chemical. Two design approaches can be applied: selecting components with sufficient strength against maximum load and protecting parts against excessive stresses. 
- System structure level. Where increased reliability is not attainable, reliability allocation is conducted in the system structure level for complex systems to enable an increase of system reliability, by adding suitable redundancy. It must be noted that redundancy has advantages and disadvantages. The main advantage is that it is the quickest way to improve reliability. The major disadvantage is the increased cost but additionally redundancy may involve sensors and switch units being introduced further increasing cost whilst at the same having an impact on reliability due to sensor failure. The use of redundancy may increase the system size, weight and/or power constraints, whilst at the same time increasing maintainability requirements. Fault tolerance is an alternative way to improve system reliability. Fault tolerance requires at least five necessary functions: fault detection, fault isolation, fault containment, fault masking, and fault compensation.

- Component level. Using proven and highly reliable items improves system reliability, but such items are subjects to item acquisition cost analysis, as the more reliable item often costs more.

Maintainability design can be undertaken within three levels.

- Operating environment level. In this level, with the use of common hand-tools and local stocking of spares can be improve availability.

- System structure level. Through reducing the need for adjustment and using built-in self-test and indicators maintainability from the system structure level can be improved.

- Component level. By selecting items that are easy to maintain and replace, the time taken to undertake maintenance can be reduced, leading to improved operational availability.

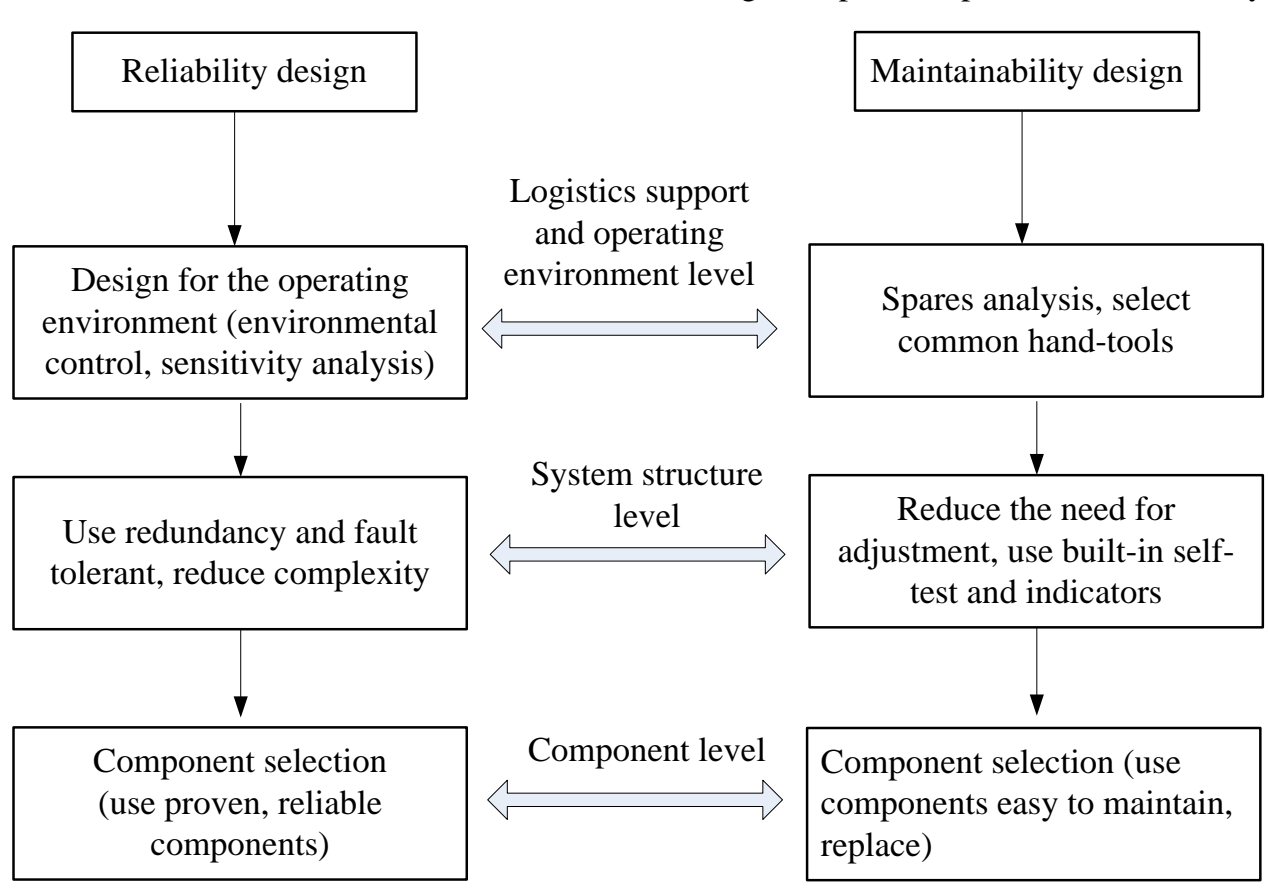

Figure 3 Reliability and maintainability design

Maintainability is a design characteristic whereas maintenance is a consequence of design. Maintenance schedules of building systems are usually developed based on HVCA (Heating, 
Ventilation, and Air Conditioning) schedules, manufacturers' recommended maintenance requirements and the operating environment. There are four types of maintenance for building systems.

- Test and inspection. Some equipment, for example, fire alarm systems, need testing and inspecting regularly to meet legislation requirements.

- Corrective maintenance. This is carried out to eliminate the effect of failure.

- Preventive maintenance. From Reliability Centred Maintenance (RCM) studies, it is feasible to introduce scheduled preventive maintenance, sometimes called Scheduled Maintenance, to reduce occurrences of failure.

- Conditioned maintenance. Through monitoring of the system, sub-system or equipment, it is feasible to predict imminent failures in sufficient time for maintenance to be carried out, avoiding incidents of catastrophic failure, such as an aircraft engine.

Figure 4 is a maintenance logic tree, which is amended from 'a maintenance logic tree' of the Whole Building Design Guide website. The words in italic and another process is the economic loss significant' have been added to the tree: preventive maintenance is only conducted if the accumulated economic loss is not significant. 


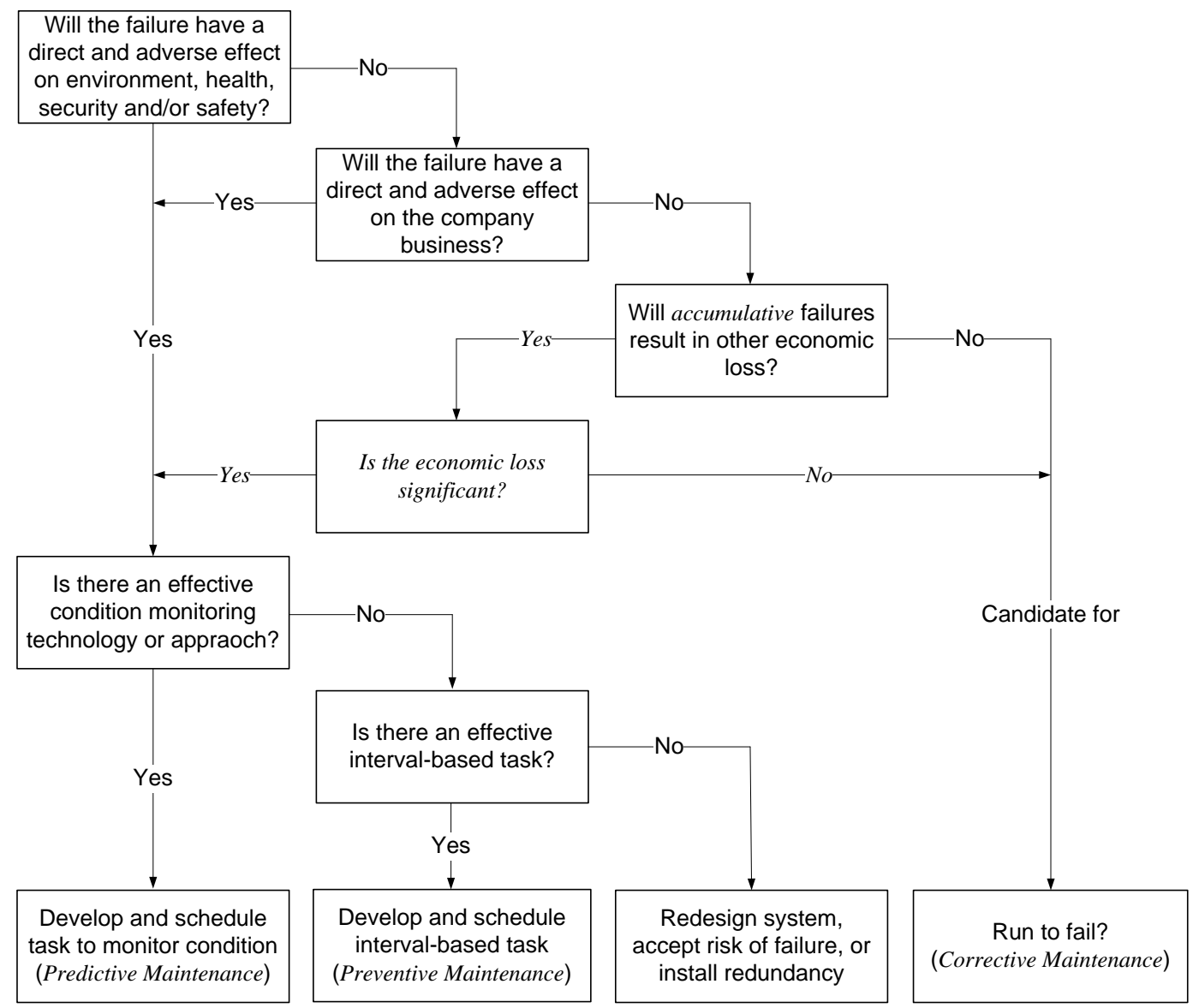

Figure 4 Maintenance logic tree amended based on 'a maintenance logic tree' from Whole Building

Design Guide website (Pride, 2004)

There is a wide variety of information technology (IT) application in building systems. Such applications may be desktop computers, inter-net access, intra-net, and specialised software for security and/or facilities management operations. All of the associated software needs to be properly maintained. The maintenance may involve updating software versions, changing user's requirements and/or improving software quality.

Software maintenance costs are usually not taken into account at the software development stage. Some software engineering researchers such as (Martin and McClure, 1983, Kusters and Heemstra, 2001) compare software maintenance with icebergs. Similar to icebergs where $90 \%$ cannot be seen above the water level, software maintenance costs can make up to $80 \%$ of the overall cost throughout the life cycle of a software product. Sommerville (2001) states that "it is difficult to find up-to-date figures" about the maintenance efforts spent by large organisations.

Training needs should be considered at the design stage, both for the operation of the system and its maintainability.

\subsection{Installation \& Commissioning}

Equipment needs to be installed properly to ensure its inherent reliability is not degraded. For example, mechanical seals are precision devices, with faces lapped within one-micron flatness. Such seals can be costly, and the installation procedure can determine how much of the dollar value spent is actually realized. With the increase in multicraft personnel doing seal installations, correct procedures become 
even more important to assure reliability retention and to gain the value from the product (Azibert and Burke, 1999).

\subsection{Operation \& Maintenance}

Based on collected data, maintenance policies may be re-developed or updated to adapt the practical use and operating environment by optimising life cycle cost and/or life cycle performance.

Generally reliability data comes from three sources: that provided by manufacturers, that accumulated from experience or historical database, or from data collected from in-service systems. Historical data on reliability and maintenance, or experience on maintenance policies is not so perfect that it can be used for statistical processing purpose. Data collected from in-service systems is also noisy and as such tends to lead to inaccuracy. For example, Briggs et al. (1998) conducted a reliability and availability modelling program that is designed to perform reliability analysis using component operational and maintenance data on 234 items in the categories of power generation, power distribution, and heating, ventilation, and air conditioning. They collected reliability data and built a reliability database. They estimated only $10 \%-20 \%$ of the data in the database was perfect data. The rest of data needed further pre-processing prior to undertaking statistical analysis (see Figure 5). A possible reason for the inaccuracy could be inadequate Fault Reporting And Corrective Action System (FRACAS) action, and/or inadequate Defect Reporting And Corrective Action System (DRACAS) action. The lack of historical maintenance records is sometimes driven by outsourced maintenance personnel 'modus operandi', repair as quickly as possible and restore the service minimising downtime and meeting terms and conditions of the contract. More cynically put, there is no income benefit to the outsourced maintenance company to improve reliability by retaining detailed unscheduled (corrective) maintenance data to be past back to the designer.

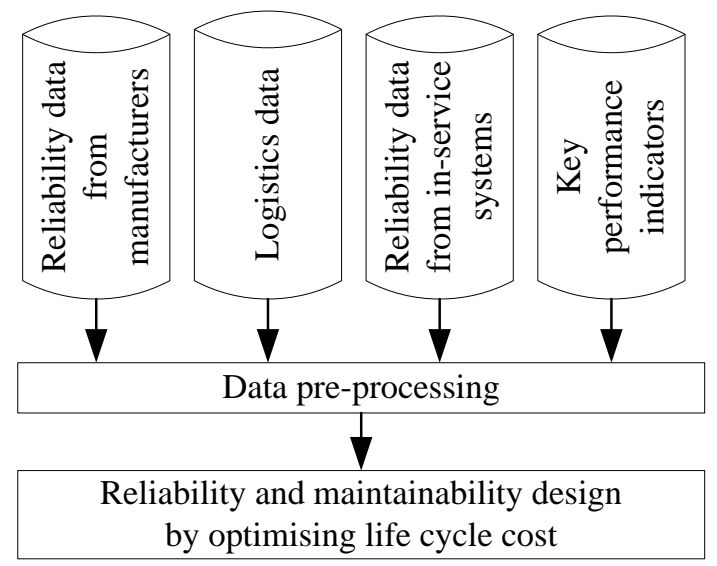

Figure 5 A data processing flow chat

\subsection{Disposal/Reusing/Recycling}

Residual value is the net worth of a system inserted at the end of the Life Cycle Cost Analysis (LCCA) study period. Since a LCC is a summation of costs, there may be a residual value associated with the building at the end of the study period. For example, there is value in a ventilation system recently been replaced or in the superstructure if the building's superstructure could function for another thirty years in a different role. 


\subsection{Useful reading materials}

Theoretically, a wide spectrum of research on design for reliability can be found from literature. Reliability design is usually referred to as reliability optimisation. For complex systems, various approaches have been introduced to optimise different objectives. The reader is referred to Kuo and Prasad (2000) for more comprehensive discussion on this topic.

Developing the maintenance policy is also a well researched topic. The reader is referred to Pham and Wang (1997), Wang (2002) and Scarf (1997) for detailed and comprehensive discussions on the theoretical aspects and the application of models in maintenance.

The following two websites are also worthwhile references for engineers as they contain information from cases studies to theoretical background.

$$
\text { www.weibull.com }
$$

www.itl.nist.govldiv898\handbooklindex.htm

\section{Analysis of a questionnaire}

Whilst building designers recognise the importance of reliability, limited reliability data exist to justify the selection of materiel. Similarly, little or no data is recorded to support selecting of materiel based upon 'design for maintainability.' Another aspect to consider is the designer does not subsequently repair, so design for repair does not feature on his 'radar screen.'

To understand better the state of the art of the application of reliability design, maintainability design, and maintenance policy development in building systems in UK, a questionnaire was designed and circulated consisting of 17 main questions. Questions were categorised into three classes: company information, reliability design, and maintainability design and maintenance policy selection.

Based on company information from our industrial partner dataset, 216 questionnaires were sent by surface mail. Out of the questionnaires, the total number of respondents was 28 . This means that the response rate is only 13\%. As Mitchell and Jolley (1996) warned, even if one starts with an unbiased sample, by the end of the study the sample may become biased because people often fail or refuse to respond to a questionnaire. They showed that a typical mail survey response rate might reach only 10 percent. The response rate is regarded therefore as acceptable.

A range of questions from the questionnaires were analysed as follows.

\subsection{Company information}

The first two questions asked the age and size of the company. Based on the respondents, one of the 28 companies had been in business between 11 years and 20 years, whereas the remainder of the companies had been in business more than 21 years. Of all the companies, seventeen companies employ more than 500 staff.

Question 3 asks about the company's main business. Some of companies may involve more than two areas. As shown in Figure 6, of the total respondents, 17\% engage "building services design". However, all of them are from the construction industry and consider reliability important in their business. 


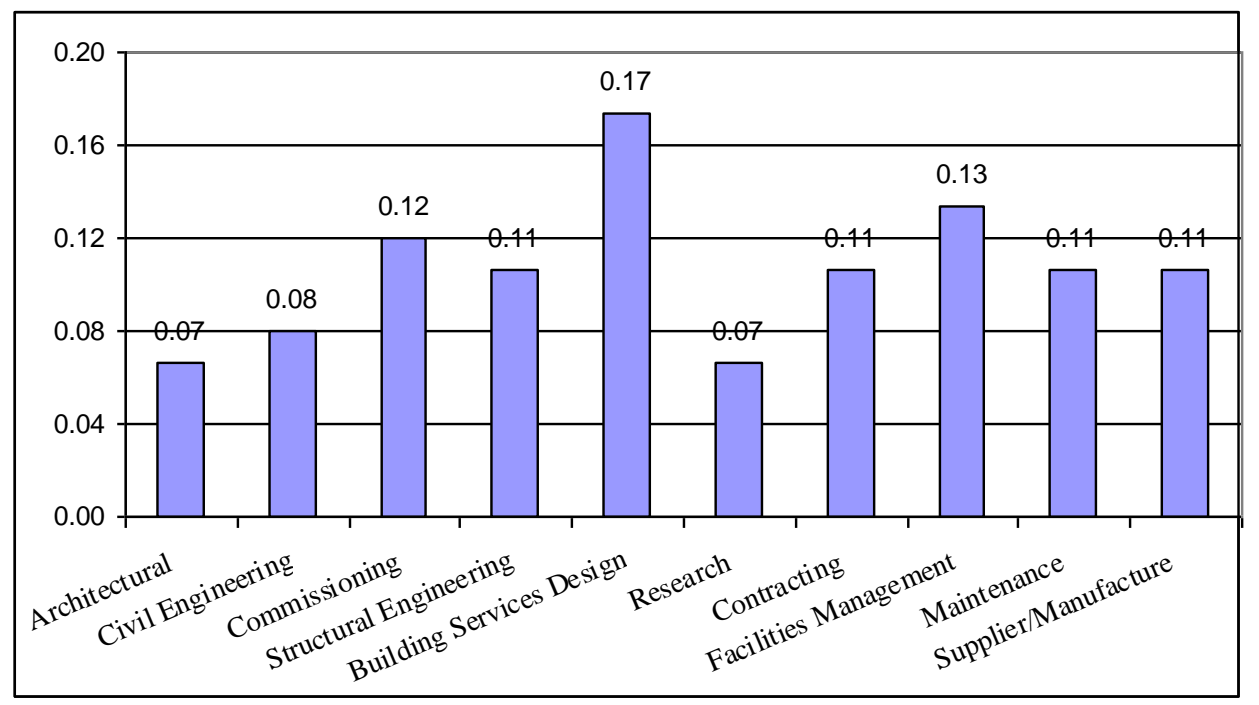

Figure 6: What kind of services does your organisation provide?

\subsection{Reliability/Maintainability Design}

In this section, questions were designed to identify how reliability and lifecycle costing have been used in the UK construction industry.

In the question "Do you take LCC into account when designing reliability for systems?", only

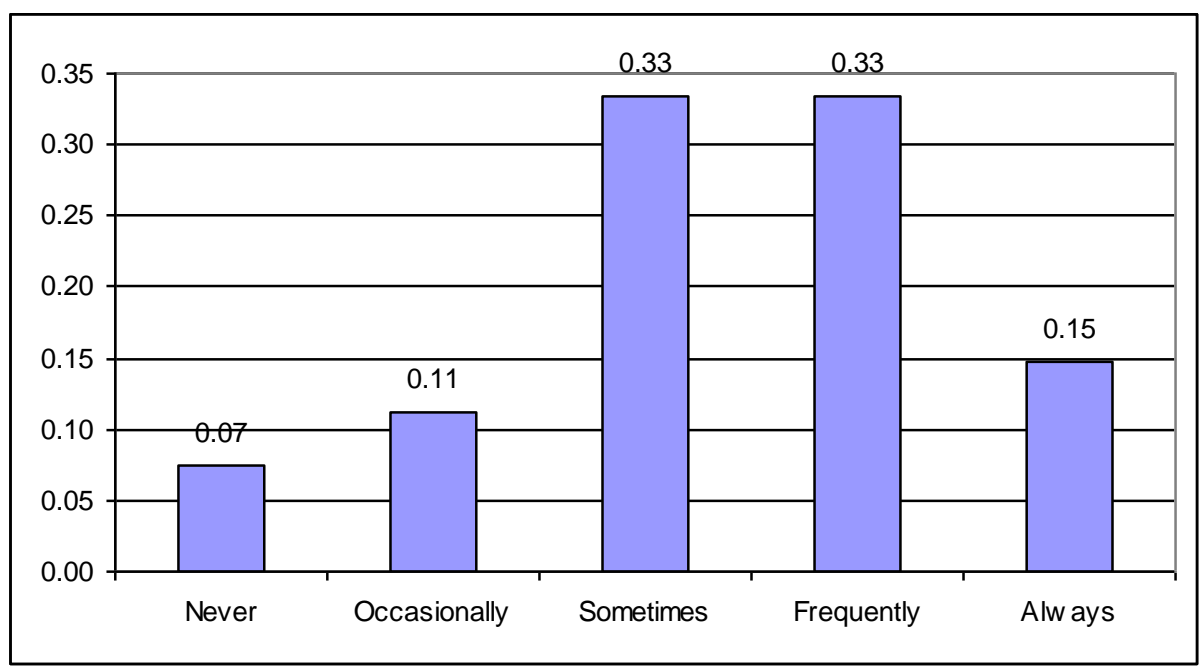

Figure 7: Do you take LCC into account when designing reliability/maintainability for systems?

$7 \%$ of the respondents answer that they never do that, whereas $48 \%$ always or frequently take life cycle costing into account when designing reliability for systems. 
When being asked 'Does your organisation use any standard for design for reliability/maintainability?' $70 \%$ of respondents design their systems using standards (see Figure 11). Standards such as British Standards (1992) are guides for reliability and/or maintainability design.

Figure 8: Does your organisation use any standard for design for reliability/maintainability?

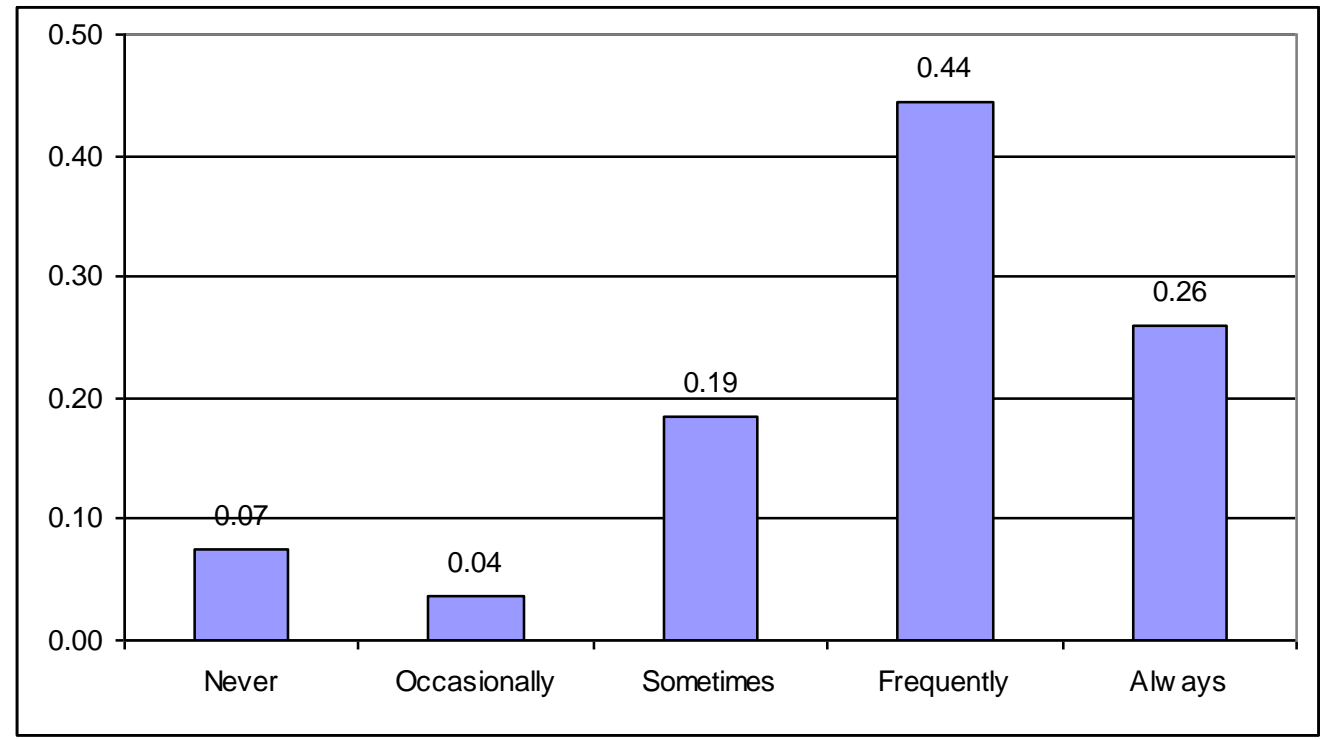

Among the respondents, availability/reliability design and maintainability allocation are the most often used approaches. Figure 12 shows that availability allocation (or reliability allocation for un-repairable systems) is the most frequently used approach in this industry.

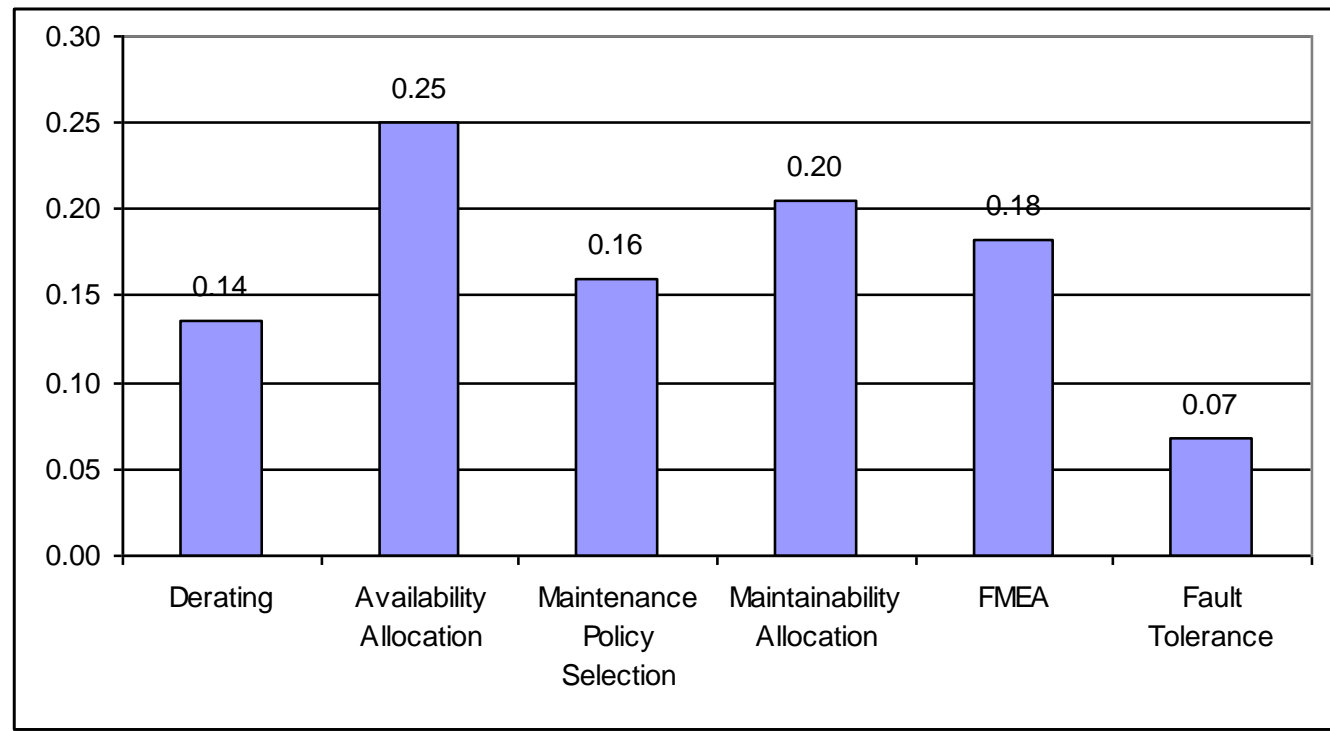

Figure 9: Do you usually use the following approaches during the design for reliability/maintainability?

Companies may design their systems on the basis of different objectives. The first column in Table 3 shows a list of objectives. Response was based upon the level of emphasis placed against each objective. It can be observed "health and safety requirement" is the most important whereas manufacturing recommendation has been paid less attention. 


\begin{tabular}{|c|c|c|c|c|c|}
\hline & N/A & Unnecessary & Not Important & Important & Very Important \\
\hline Cost competitiveness & 0 & 0 & 2 & 12 & 13 \\
\hline Product quality & 0 & 0 & 0 & 14 & 13 \\
\hline $\begin{array}{l}\text { Health and safety } \\
\text { requirements }\end{array}$ & 1 & 0 & 0 & 7 & 19 \\
\hline $\begin{array}{l}\text { Environmental } \\
\text { requirements }\end{array}$ & 1 & 0 & 1 & 19 & 6 \\
\hline $\begin{array}{l}\text { Manufacturing } \\
\text { recommendation }\end{array}$ & 0 & 2 & 8 & 12 & 5 \\
\hline Company policy & 1 & 2 & 5 & 13 & 6 \\
\hline $\begin{array}{l}\text { Breakdown cost } \text { (lost } \\
\text { production) }\end{array}$ & 3 & 0 & 4 & 11 & 8 \\
\hline Replacement cost & 1 & 0 & 6 & 13 & 7 \\
\hline Availability & 1 & 1 & 2 & 13 & 10 \\
\hline Investment costs & 1 & 1 & 4 & 15 & 6 \\
\hline Reliability & 0 & 0 & 0 & 9 & 18 \\
\hline
\end{tabular}

Table 3: How much emphasize is placed on each of the following factors when designing the system for reliability of the system?

As known, failure information (for example, mean time to failure (MTTF), mean time between failure (MTBF), mean time between repair (MTBR), mean time between maintenance (MTBM)) are factors for maintenance policy design. Recording operating data and failure information are therefore important. Figure 10 shows that $56 \%$ of the respondents always record maintenance information for systems. This figure also shows that only a small fraction of companies discard such information.

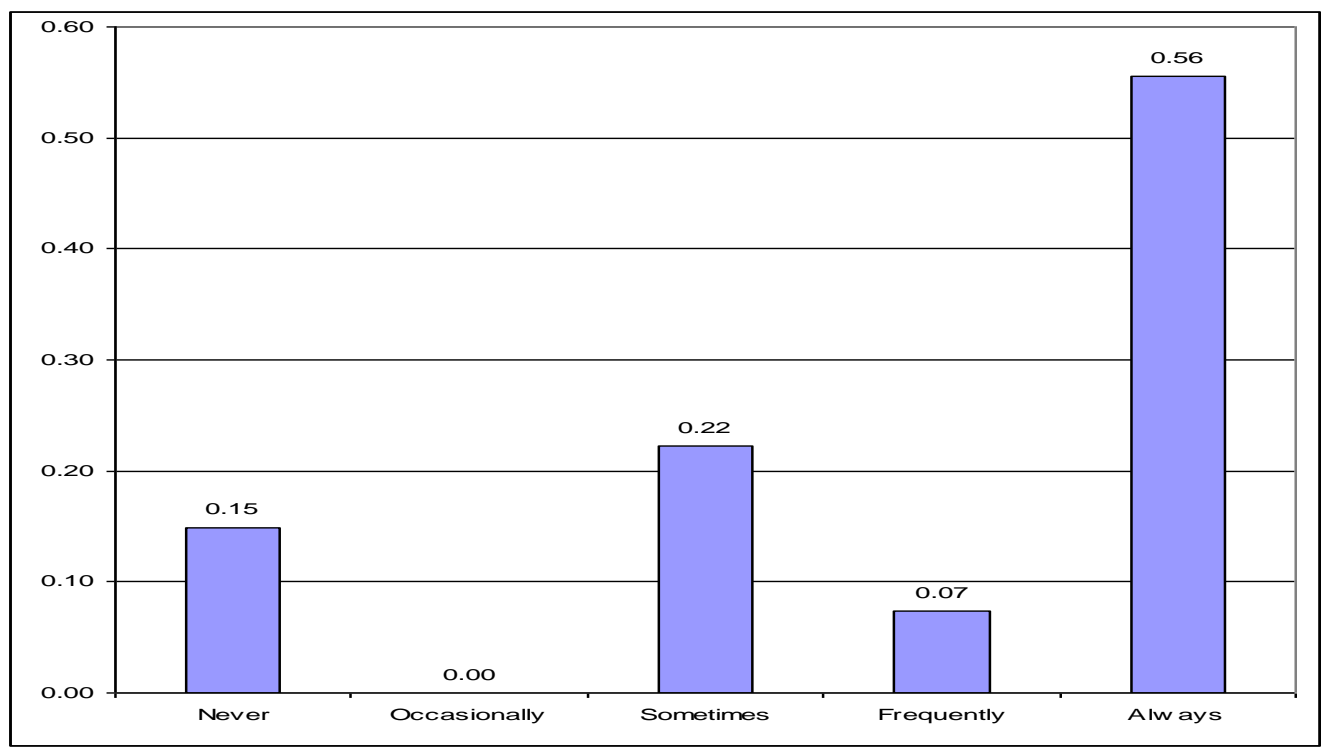

Figure 10: Do you record details about the maintenance for systems? 
Following the above question, when being asked, "Do you use historical data as the purpose of improving the reliability of your systems?" Figure 11 shows that only $14 \%$ of the respondents answered they ALWAYS do, yet 56\% of the respondents ALWAYS record information about the maintenance for systems" shown in Figure 10, 42\% (56\%-14\%=42\%) of companies do not always utilise their records further in maintenance policy design. The purpose of maintenance records justifies

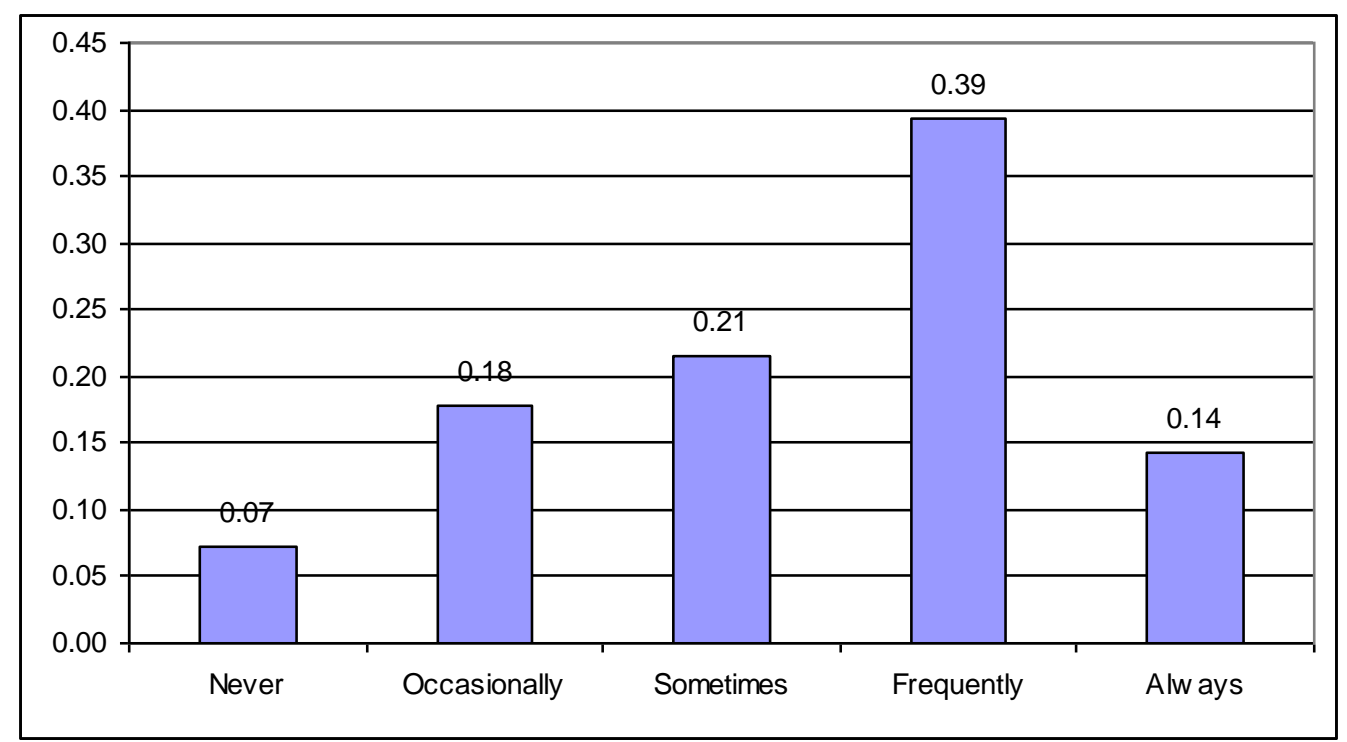

further analysis, it is possible records are retained for payment and financial audit and not used to improve design for reliability nor maintainability

Figure 11: Do you use historical data as the purpose of improving the reliability of your systems?

\subsection{Maintenance Policy Selection}

Maintenance policy development has received much attention in reliability literature. For the purposes of this paper, five methodologies for maintenance policy selection are listed: failure-based maintenance, preventive maintenance, reliability centred maintenance, total productive maintenance, and condition-based maintenance. Among these policies, preventive maintenance is the most widely used by the respondents, whereas the total productive maintenance has drawn less attention. Figure 12 indicates that $45 \%$ of companies maintain their systems preventively, whereas only $5 \%$ of them use total productive maintenance. Failure-based maintenance is another name for corrective maintenance, only $23 \%$ of companies selected this maintenance policy. It is therefore assumed that the terminology "failure-based maintenance" may be misunderstood. 


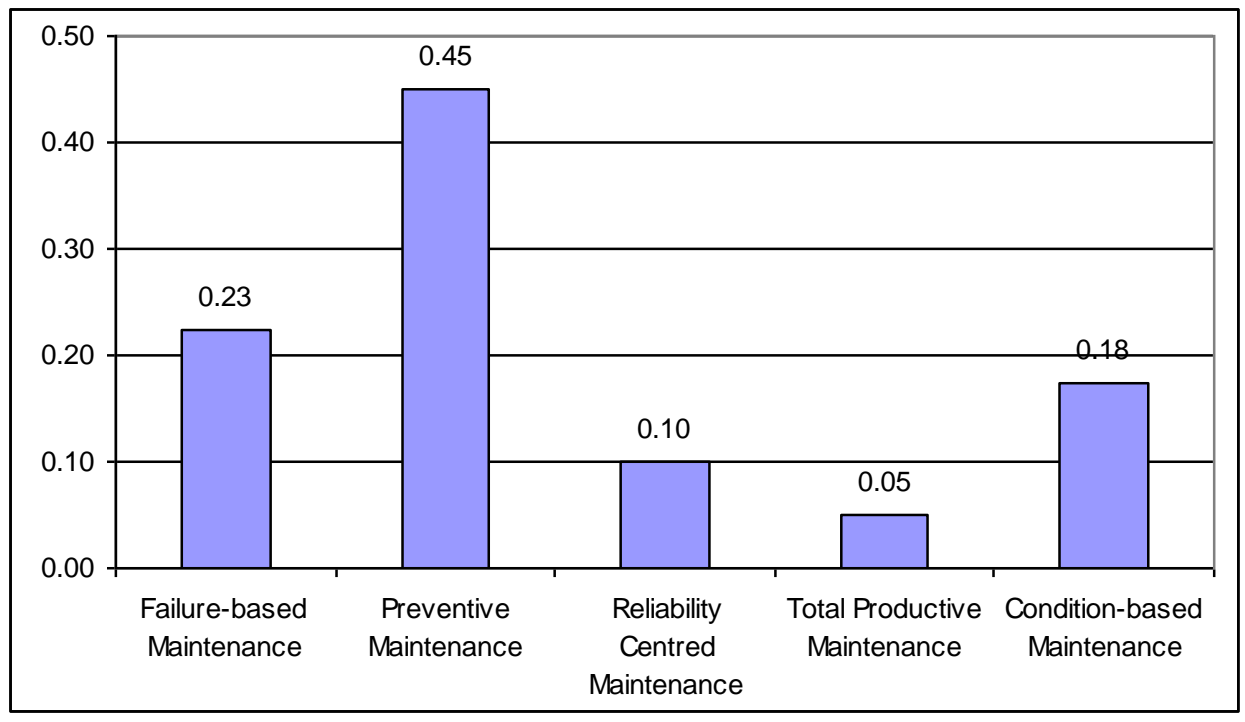

Figure 12: Which are the main maintenance policies for your systems?

In reliability literature, maintenance policies are commonly developed based on reliability data collected from manufacturers and in-service systems, for example, mean time between failures (MTBF) and mean time to repair (MTTR). These types of data have not always been used in industries, as shown in Figure 15, 63\% of the companies select maintenance policies on the basis of company's experience and knowledge. As sophisticated mathematical algorithms are needed to develop maintenance policies, which collect reliability data, it is not realistic for building managers to optimise maintenance policies without specific reliability analysis software.

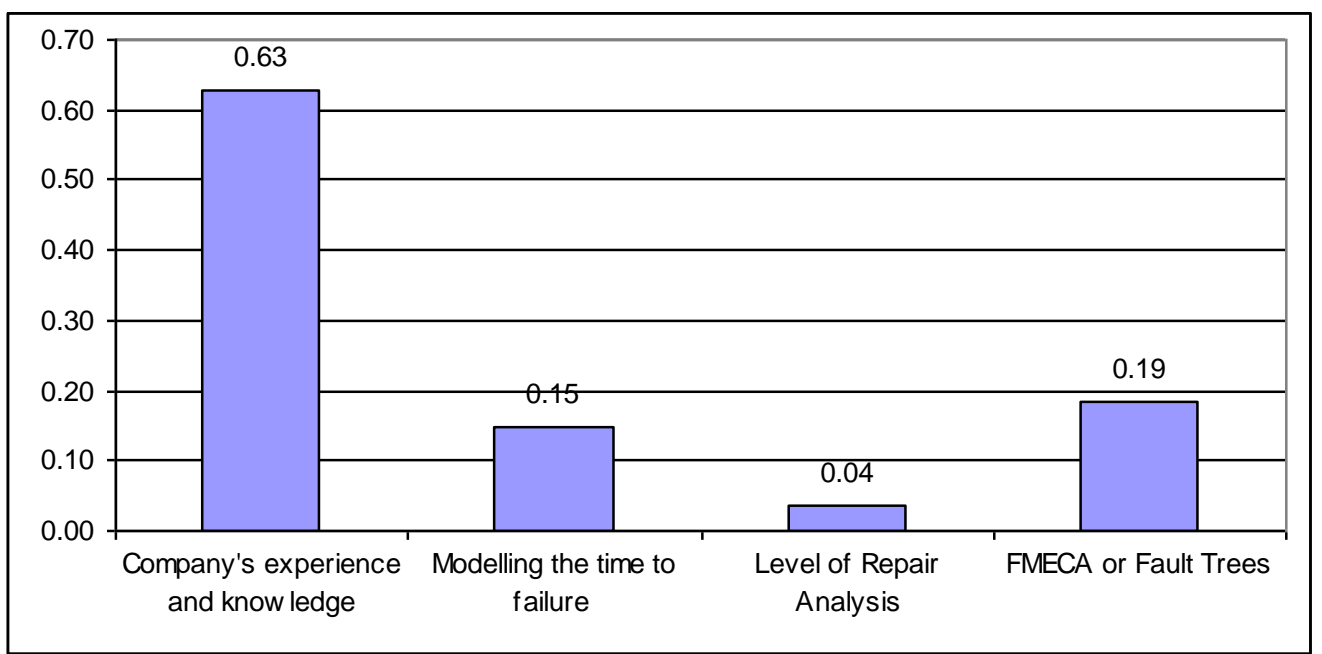

Figure 13: What are the main approaches to selecting maintenance policies?

The last question asks "How much emphasis is placed on each of the following factors when deciding or selecting a maintenance approach (strategy, policy, or technique)?" This is similar to the question and responses shown in Table 3.

\section{Conclusions}

By suitable reliability design, maintainability design and maintenance policy development, it is envisaged that lifecycle costs savings can be predicted. This paper firstly presented a methodology 
based upon integrating reliability design and maintainability design into the Through Life Business Model (TLBM), and it finally analyzed questionnaires designed for investigating the current state of the art application of reliability design and maintainability design in UK companies.

The following outcome has been achieved:

- approaches to reliability design and maintainability design have been introduced from the operating environment level, system structure level and component level;

- $\quad$ a scheduled maintenance logic tree is modified based on the resource from (Pride, 2004).

The following results have been achieved.

- although most companies keep maintenance records, few companies use historical data for the purpose of improving the reliability and maintainability of systems;

- a small percentage of companies in the construction industry use fault tolerance;

- most companies develop maintenance policies based upon their own experience;

- $\quad$ health and safety is the first priority when a maintenance policy is developed.

Based on the analysis of the questionnaire respondents, it is suggested that data analysis applied in reliability design, maintainability design, and maintenance policy development.

\section{Acknowledgements}

The authors would like to thank EPSRC as part of the Innovative Manufacturing Research Centres (ICRC) initiative for their financial support and our industrial partners (EC Harris, Dytecna Limited, EMCOR Rail, INBIS and Quorum Logistics Support).

\section{References}

Azibert, H. and Burke, W. (1999) Mechanical seal installation affects reliability, Plant Engineering, 53, 80-82.

Bartlett, E. V. and Simpson, S. (1998) Durability and reliability, alternative approaches to 17 assessment of component performance over time, World building congress, 35-42.

Briggs, S., M., B. and Arno, R. (1998) Reliability and availability assessment of electrical and mechanical systems, IEEE Transactions on Industry Application, 34, 1387-1396.

British Standard. (1992), Reliability of Systems, equipment and components -- Part 14: Guide to formal design review, BS 5760-14.

El-Haram, M. A., Marenjak, S. and Horner, M. W. (2002) Development of a generic framework for collecting whole life cost data for the building industry, Journal of Quality in Maintenance Engineering, 8, 144-151.

Evans, R., Haryott, N., Haste, N. and Jones, A. (1998), The long-term costs of owning and using buildings, The Royal Academy of Engineering, London.

IEEE (1990), IEEE Standard Computer Dictionary: A Compilation of IEEE Standard Computer Glossaries, Institute of Electrical and Electronics Engineers, New York. 
John, G., Loy, H., Clements-Croome, D., Fairey, V. and Neale, K. (2003) Through Life Support for Building Services Systems, Worldwide CIBSE/ASHRAE Gathering of the Building Services Industry: 24-26 September 2003.

Kuo, W. and Prasad, V. (2000) An annotated overview of system reliability optimization, IEEE Transactions on Reliability, 49, 176-187.

Kusters, J. and Heemstra, F. (2001) Software maintenance: an approach towards control, IEEE International Conference on Software Maintenance, IEEE Computer Society, 667-670.

Martin, J. and McClure, C. (1983) Software Maintenance: The Problem and Its solutions Englewood Cliffs, Prentice Hall, New Jersey.

Mitchell, M. L. and Jolley, J. M. (1996) Research design explained, Harcourt Brace College Publishers, Fort Worth.

MOD-UK-DEF-STAN-00041 Reliability and Maintainability MoD Guide to Practices and Procedures. Moubray, J. (1996) RCM-II-Reliability-centred Maintenance, Butterworth-Heinemann, Oxford.

Pham, H. and Wang, H. (1997) Imperfect maintenance, Quality Control and Applied Statistics, 42, 225-226.

Pride, A. (2004) http://www.wbdg.org/design/resource.php?cn=0\&cx=0\&rp=26\#footnote1.

Scarf, P. A. (1997) On the application of mathematical models in maintenance, European Journal of Operational Research, 99, 493-506.

Sommerville, I. (2001) Software engineering, Pearson Education Ltd, Harlow.

Wang, H. (2002) A survey of maintenance policies of deteriorating systems, European Journal of Operational Research, 139, 469-489. 